\title{
DECLARACIÓN INSTITUCIONAL DE LA UNIVERSIDAD LOYOLA ANDALUCÍA SOBRE EL DESARROLLO
}

El trabajo en desarrollo en la Universidad Loyola Andalucía es más antiguo que la propia Universidad. Habría que remontarse a los inicios de ETEA en los años 60 del siglo pasado para encontrar las primeras actividades en este campo. La Fundación ETEA para el Desarrollo y la Cooperación, hoy Instituto de Desarrollo de la Universidad Loyola, ha jugado un papel clave en ese trabajo desde su constitución en 2002.

Como institución de la Compañía de Jesús, la aspiración a una sociedad global justa, la justicia en términos generales y la justicia económica en particular, ha dado en el pasado y continúa dando en la realidad actual de la Universidad Loyola Andalucía, perspectiva, contexto y fundamento a la presencia significativa del trabajo en el campo del desarrollo como contribución a la generación de "condiciones de vida más humanas". De alguna manera, la lucha por la justicia, como preocupación vital de la Compañía de Jesús, explica por qué el desarrollo, entendido como humano e integral, solidario e inclusivo, sostenible, está llamado a ocupar un lugar preferente en las actividades de esta Universidad.

Esa preocupación y compromiso con la justicia global, con el acompañamiento y apoyo a los más desfavorecidos, es lo que se recoge en la Declaración Institucional de la Universidad Loyola Andalucía sobre el Desarrollo que aquí se presenta, alineada con la tradición y $\mathrm{Mi}$ sión de la Compañía, su magisterio y la inspiración de documentos recientes de la misma, como son las Preferencias Apostólicas Universales y el Proyecto Apostólico de Provincia.

Francisco Amador, Coordinador de la Comisión de Desarrollo de la Universidad Loyola Andalucía.

El desarrollo es un proceso social, en sentido amplio, multidimensional. Un proceso que es abordado desde disciplinas diferentes, pero complementarias, que definen los factores determinantes que lo promueven o frenan, estudian la naturaleza de los procesos que engloba e identifican los instrumentos de análisis y acción más eficaces para favorecerlo.

La Universidad Loyola Andalucía, siguiendo el enfoque de Pablo VI, para quien el desarrollo implica "el paso para todos y cada uno de condiciones de vida menos 
humanas a condiciones más humanas", concibe que el auténtico desarrollo ha de ser humano e integral, inclusivo y solidario, sostenible. Desde una perspectiva cristiana, esta tarea se revela como continuadora de la obra creadora de Dios que ha puesto en manos de la humanidad la casa común a cuidar y compartir con todos los seres del universo.

El desarrollo es humano e integral en la medida en que atiende a la persona humana completa, como persona que quiere desplegar todas sus potencialidades $y$ capacidades y hacer realidad sus aspiraciones, tanto en cuanto individuo, como en cuanto ser relacional. El desarrollo, pues, sólo es posible si implica a los otros, si se realiza abierto a los otros, no solo a través de intercambios materiales, sino mediante relaciones basadas también en la reciprocidad y la gratuidad.

El desarrollo ha de ser inclusivo en la medida en que quiere llegar a todos; con especial atención a los más vulnerables, y busca que todos sean tratados en pie de igualdad como sujetos de los derechos humanos, que son la base de la convivencia de los pueblos y de la humanidad entera.

El desarrollo ha de ser solidario en la medida en que considera a las personas no solo como destinatarios, sino como artífices individuales y colectivos del propio desarrollo; en un esfuerzo inspirado, no solo por una sana competencia, sino sobre todo por la cooperación entre todos de forma que los problemas de cada uno sean problemas de todos, abordados con recursos de todos y afrontados con una solidaridad a la vez espontánea e institucionalizada y organizada.

El desarrollo ha de ser sostenible en la medida en que es consciente de la limitación de los recursos naturales a disposición de nuestra generación y de las generaciones futuras; y eso implica administrar y gestionar el patrimonio que nos ha sido confiado con responsabilidad, no como una realidad a conquistar y dominar, sino como la casa común que hemos de cuidar con respeto y esmero y compartir con todos.

Por consiguiente, la persona humana es el centro (porque le da su último sentido), el fin (porque es su meta) y el sujeto (porque es agente y no solo beneficiario) del desarrollo humano. Ahora bien, las personas viven en sociedades organizadas según determinadas estructuras e instituciones. Esto implica, en consecuencia, el análisis crítico de esas estructuras para ver si ayudan al objetivo humano que hemos formulado, así como la búsqueda de vías para mejorarlas o cambiarlas en caso de que no sean las adecuadas. El compromiso por un desarrollo justo no se limita a una acción dirigida a las personas, abarca también el esfuerzo de transformación de la sociedad, sus estructuras e instituciones. 